\title{
LA MEDICIÓN DE LAS ACTITUDES ANTE LA INMIGRACIÓN: EVALUACIÓN DE LOS INDICADORES TRADICIONALES DE «RACISMO»
}

\section{M. a Ángeles Cea D’Ancona}

Universidad Complutense de Madrid

\begin{abstract}
RESUMEN
En los últimos años han ido en aumento las críticas a la eficacia de las encuestas convencionales en la medición de las actitudes «reales» ante la inmigración. El presente estudio evalúa el grado de efectividad de los indicadores tradicionalmente incluidos en dichas encuestas. Se analizan encuestas del CIS (estudios 2214, 2383 y 2498), que se comparan con las realizadas por CIRES/ASEP, CEMIRA y Eurobarómetros de las Comunidades Europeas. Mediante un análisis de componentes principales de los 41 indicadores seleccionados del primer estudio del CIS, se obtienen 10 dimensiones del concepto de racismo. La contribución de cada dimensión se comprueba mediante un análisis discriminante. En consonancia con las nuevas propuestas de racismo, los items relativos a derechos sociales y de ciudadanía son los de mayor utilidad en la medición de las actitudes ante la inmigración, seguidos de los relativos a política inmigratoria, en menoscabo de los consagrados indicadores de racismo. Además, el análisis de conglomerados k-medias confirma la limitación de dichas encuestas para captar la actitud contraria a la inmigración (sólo un $6 \%$ de los encuestados queda clasificado como reacio a la inmigración). De los análisis se concluye la necesidad de introducir modificaciones en el instrumento de medida para mejorar la captación de la actitud «real» ante la inmigración.
\end{abstract}

Desde sus orígenes, el estudio de las actitudes suscita controversia. La controversia atañe no sólo a su definición, sino también al proceso a seguir en su medición. Respecto a su definición, Allport recopiló más de cien definiciones del término actitud en un estudio pionero (editado en 1935 con el título gené- 
rico "Attitudes» $\left.{ }^{1}\right)$. Entonces, este autor se decantó por una concepción de la actitud llamada "mentalista» (Ros, 1981), al describirla como un estado neuropsíquico de disposición previa a una conducta concreta ante estímulos específicos. Con posterioridad, Katz (1974: 281) definió la actitud como «una predisposición del individuo a valorar ciertos símbolos u objetos o aspectos de su mundo de un modo favorable o desfavorable». Otros autores, en cambio, se han decantado por la propuesta de Osgood et alía $a^{2}$, donde se subraya el componente "conductual» de la actitud. Ésta pasa a concebirse como respuesta ante un determinado objeto. Así, Lamberth (1980: 217) la define como «una respuesta evaluativa, relativamente estable, en relación a un objeto, que tiene componentes o consecuencias cognitivas, afectivas y probablemente comportamentales». El interés de su estudio estaría en comprobar si las actitudes son "causas» de conductas (McBroom y Reed, 1992). En caso afirmativo, su conocimiento permitirá no sólo predecir la conducta, sino también modificarla o controlarla, cambiando la actitud. Si bien, Katz (1974) ya puntualizó que dicha posibilidad de cambio se complica cuando la actitud está relacionada con un sistema de valores conexos (es decir, un sistema de valores estrechamente vinculado al concepto que el individuo tiene de sí mismo).

En cuanto a su medición, se ha discutido extensamente acerca de la idoneidad del procedimiento seguido con mayor frecuencia; a saber, la inferencia de la actitud a partir de las declaraciones verbales de los sujetos. "La medida de actitudes se basa en el supuesto de que las expresiones verbales, orales o escritas, son una pantalla física en la que la gente revela sus contenidos actitudinales invisibles psíquicos» (Pastor, 1978: 406). Ya en 1934, Lapiere (en su artículo "Attitudes vs. Actions», publicado en la revista Social Forces) cuestionó la validez de las respuestas verbales en la medición de las actitudes. Mediante un cuestionario se puede obtener una reacción verbal ante una situación enteramente simbólica, que no coincide necesariamente con la actuación real del entrevistado cuando se encuentre ante dicha situación. No existe seguridad al respecto. En el mismo sentido se han pronunciado autores posteriores. Véase Alvira (1977), quien, tras una revisión de estudios sobre actitud y conducta, concluye que las mediciones verbales de las actitudes no son adecuadas como medidas de las actitudes subyacentes; no obstante, reconoce que ésta continúa siendo la estrategia más seguida en la medición de las actitudes.

En España son varios los estudios que, tanto desde la esfera privada como desde la pública, han ido describiendo, de forma sistemática, especialmente a partir de 1990, el fenómeno cada vez más presente de la «inmigración». Destacan las encuestas específicas sobre actitudes ante la inmigración del Centro de Investigaciones Sociológicas (CIS: 1990, 1991, 1993, 1995, 1996) y los barómetros de enero de 2000 y de febrero de los años 2000 y 2001; las realizadas

${ }^{1}$ En la compilación realizada por C. Murchison, $A$ handbook of social psychology, Worchester, Mass., Clark University Press, pp. 798-844.

2 The measurement of meaning, Illinois, University of Illinois Press, 1957. 
por el Centro de Estudios sobre la Realidad Social (CIRES: 1991, 1992, 1993, 1994, 1995), que posteriormente se transforma en Análisis Sociológicos, Económicos y Políticos, S.A. (ASEP: 1996, 1997, 1998, 1999, 2000), unas y otras bajo la dirección de Díez Nicolás; y las efectuadas por el Centro de Estudios sobre Migraciones y Racismo de la Universidad Complutense de Madrid (CEMIRA: 1990, 1995, 1997), bajo la dirección de Calvo Buezas. Asimismo, sobresalen los estudios cualitativos del Colectivo IOÉ (1995).

La mayoría de las encuestas referidas comparten la utilización de unos mismos indicadores en la medición de las actitudes de la población autóctona ante la inmigración exterior, aunque difieren en su disposición en el cuestionario, en la formulación concreta de las preguntas y las opciones de respuesta. A través de dichas encuestas se quiere analizar la evolución de las actitudes de los españoles ante la inmigración, mediante la práctica de un diseño de investigación longitudinal de tendencias, en el caso de las encuestas del CIS y CIRES/ ASEP. En distintas fechas se pasa el mismo cuestionario (en ocasiones ligeramente modificado) a una muestra aleatoria de la población de 18 y más años residente en las distintas Comunidades Autónomas de España. En las encuestas de CIRES/ASEP el tamaño muestral se mantiene constante en todos los sondeos de opinión (1.200 casos, aproximadamente), pero no en las encuestas del CIS, que difiere en cada fecha de encuesta. Su análisis permite no sólo conocer las «tendencias» en la población española de las actitudes "declaradas» ante la inmigración, sino también comprobar la «fiabilidad» del instrumento de medición aplicado: el cuestionario. De acuerdo con McBroom y Reed (1992: 205): «Los datos longitudinales proporcionan una ventaja de diseño importante al estudiar la consistencia actitud - conducta».

Lo que se cuestiona es la capacidad de las encuestas para descubrir la actitud «real» de la población autóctona ante la inmigración exterior, ya sea por razones de diseño del cuestionario (el efecto de la formulación y de la ubicación de las preguntas en el cuestionario), ya por el medio mayoritariamente seguido en la aplicación de los cuestionarios: la entrevista personal (el «efecto del entrevistador»). A ello hay que añadir otro elemento clave a incorporar en la evaluación de dichas encuestas: la medición del concepto de "racismo». Existen distintos tipos de racismos, que van desde el llamado «biológico» (el que tradicionalmente se mide en los sondeos de opinión) hasta otras modalidades más sutiles, llámense racismo «moderno»" «simbólico»" «aversivo» (que es la

3 Desarrollado por J. B. McConahay en 1983 («Modern racism and modern discrimination: the effects of race, racial attitudes and context on simulated hiring decisions», Personality and Social Psychological Bulletin, 9, 551-558).

4 J. B. McConahay y J. L. Hough, Jr. (1976), «Symbolic racism», Journal of Social Issues, 32, 23-45. También destaca la contribución de D. R. Kinder y D. O. Sears (1981), «Prejudice and politics: symbolic racism versus racial threats to the good life», Journal of Personality and Social Psychology, 40, 414-431.

5 Acuñado por S. L. Gaertner y J. F. Dovidio en 1986 ("The aversive form of racism», en Dovidio y Gaertner [comps.], Prejudice, discrimination and racism, San Diego, Academic Press). 
forma menos extrema de discurso racista) o «prejuicio sutil» ${ }^{6}$, que se «solapan en contenido y están positivamente intercorrelacionadas» (Meertens y Pettigrew, 1997: 68). Pero en las encuestas no siempre se incluyen indicadores de las distintas modalidades de racismo. Como afirma Izquierdo (1996: 154): «El actual formato de las encuestas no alcanza a poner en evidencia las diversas expresiones racistas y xenófobas que cada clase social genera y oculta en las entrevistas (...) Creo que cada vez más las capas medias saben cómo sortear en los sondeos de opinión la pregunta que retrata el racismo sencillo de los más desfavorecidos y que, a las nuevas generaciones, hay que presentarles otras cuestiones y hacerlo de modo distinto para detectar el rostro oculto de los diversos racismos. Y quizás también sea necesario emplear otros instrumentos para revelar lo que de un modo general se considera que es impresentable». Estas aseveraciones insisten en la necesidad de introducir modificaciones en el instrumento de medida para captar mejor la actitud «latente» ante la inmigración. Asimismo, parece deseable el uso complementario de otras estrategias de investigación, además de la encuesta.

En el estudio específico de las actitudes ante la inmigración se insiste en la necesidad de diferenciar las dos vertientes de la actitud: la manifiesta y la latente (Pérez, 1996). "Ambas vertientes o dimensiones no son siempre coincidentes. Se puede sentir animadversión o rechazo ante la presencia de personas extranjeras (o de etnia diferente) y, en cambio, no exteriorizar dicho sentimiento. Depende, principalmente, de la licitud que el grupo social de referencia atribuya a la manifestación de actitudes racistas» (Valles, Cea e Izquierdo, 1999: 79). «En las sociedades actuales avanzadas sólo determinadas minorías bien identificadas manifiestan de forma abierta actitudes racistas. La mayoría rechaza el racismo, si bien sólo en el plano manifiesto, ya que en el plano latente sigue aceptándolo» (Morales y Páez, 1996: 12). Solé y Herrera (1991) corroboran esta disparidad entre lo "manifiesto» y lo «latente» al detectar, mediante una encuesta a 238 inmigrantes en Cataluña, que una elevada proporción de ellos (el 98,6\% de los africanos y el 48\% de los marroquíes encuestados) han sufrido alguna actitud racista por parte de la población autóctona. La situación objetiva de discriminación real la muestran a través de los indicadores de empleo, educación y vivienda ${ }^{7}$.

${ }_{6}$ T. Pettigrew y R. W. Meertens (1995), «Subtle and blatant prejudice in Western Europe», European Journal of Social Psychology, 25, 57-75.

En un estudio reciente (Díez Nicolás y Ramírez Lafita, 2001) se niega, tras encuestar a 765 inmigrantes procedentes de África, Latinoamérica y Asia, que los inmigrantes perciban un trato discriminatorio por parte de la población española, en contra de lo indicado en estudios anteriores (véanse Calvo Buezas, 1990; Solé, 1997; Leal, 1997; Martínez Veiga, 1997). Los autores se atienen al porcentaje de inmigrantes que en la encuesta declaran no haberlo sufrido: $66 \%$ en los lugares de ocio (restaurantes, bares, cines, discotecas, etc.), $62 \%$ en alquilar la casa en la que viven, $63 \%$ en la calle y $52 \%$ en el trabajo/al pedir trabajo. De su datos de encuesta creo que merece un análisis más preciso la población que sí declara haber sufrido discriminación (el 28, 33, 34 y 44\%, respectivamente), por estimar que no representan un porcentaje irrelevante, en especial en el ámbito laboral (44\%), y habría que relacionarlo con el trato que recibe la pobla- 
El presente artículo analiza la medición de las actitudes ante la inmigración, los indicadores utilizados y su efectividad. Se pospone a publicaciones posteriores la indagación sobre aspectos relacionados con el diseño del cuestionario (tipo de pregunta, formulación, su disposición en el cuestionario) y la modalidad de encuesta empleada. Para la descripción y posterior comprobación de la efectividad de los indicadores tradicionalmente incluidos en las encuestas se acude, fundamentalmente, a aquellas realizadas por el CIS. Éstas se complementan con las efectuadas por el CIRES/ASEP, CEMIRA y Eurobarómetros de las Comunidades Europeas.

De las encuestas del CIS se escoge el estudio 2214, que corresponde a la última (hasta el momento presente) encuesta ex profeso de «actitudes ante la inmigración», llevada a cabo por dicho Centro con fecha de junio de 1996, mediante entrevista personal. El ámbito de la encuesta es nacional, estando la muestra integrada por 2.493 unidades elegidas aleatoriamente (población española, de ambos sexos, de 18 y más años). Asimismo, se analizan dos barómetros del CIS referidos, igualmente, a la medición de las actitudes ante la inmigración, aunque no de forma exclusiva: los barómetros de febrero de 2000 (estudio 2383) y de febrero de 2001 (estudio 2498), dirigidos también a la población española, de ambos sexos, de 18 y más años, siendo las muestras de 2.477 y 2.498 unidades, respectivamente.

\section{LA MEDICIÓN DE LAS ACTITUDES ANTE LA INMIGRACIÓN}

La medición de las actitudes precisa de la consideración de tres componentes «esenciales» (Lamberth, 1980). Uno, el afectivo, que controla el nivel de agrado o desagrado de la persona con respecto al objeto de actitud. Esto es, la intensidad de la actitud: a favor - en contra. Dos, el cognitivo o de creencias con respecto a un objeto, que sugiere, a su vez, dos dimensiones adicionales: la especificidad o generabilidad de la actitud y el grado de diferenciación de las creencias. Tres, el comportamental o conductual, que controla cómo se comporta la persona relacionándolo con los otros dos componentes de la actitud. En el caso concreto de la medición de actitudes y prejuicios étnicos raciales es, además, característica común la inclusión de tres aspectos fundamentales (Morales, 1996):

1) Distancia social (Oskamp, 1991): grado de separación considerado aceptable en las relaciones entre personas de países o de etnias distintos. Se distingue un grado de intimidad máximo (matrimonio,

ción autóctona en las mismas situaciones. Algunas indagaciones se han hecho ya en estudios monográficos sobre inmigración y trabajo en sectores económicos específicos (construcción, hostelería, servicio doméstico) por el Colectivo IOÉ (...). En todo caso, como señalan estos últimos autores, hay que saber relativizar los datos de encuesta y los que se producen con la metodología cualitativa (Colectivo IOÉ, 2001: 334). 
noviazgo...), intermedio (vivir en el mismo vecindario, compartir los mismos clubes sociales, recreativos...) y mínimo (compartir el mismo autobús, acudir a los mismos establecimientos públicos, como bares o cafeterías...).

2) Igualdad de tratamiento: grado de aceptación de principios generales de discriminación en distintos ámbitos de la vida social (trabajo, transporte público, posibilidad de asistir a los mismos centros escolares, libertad de elección de la pareja sin tener en cuenta su raza o país de origen). No obstante, se advierte que las preguntas de los cuestionarios apuntan a principios generales, no a prácticas concretas.

3) Implementación de los principios de igualdad: grado de aceptación de políticas concretas emprendidas por el gobierno con vistas a conseguir la igualdad racial.

Los principios de igualdad de derechos están presentes en las versiones más actuales del discurso racista. Lo habitual, en dichas encuestas, es que se deduzca una actitud más negativa, hacia personas de otra etnia o país diferente, cuando se evalúan políticas gubernamentales concretas y se responde a cuestiones referidas al polo de distancia social que implica una mayor intimidad. Por el contrario, la actitud menos negativa se obtiene en preguntas sobre principios generales de discriminación y las relativas al polo de distancia social que implica una intimidad escasa (Morales, 1996).

A continuación se detallan los items, seleccionados de la encuesta del CIS de actitudes ante la inmigración de 1996, que van a servir para comprobar estas y otras hipótesis de la presente investigación. En la elección se ha tenido en cuenta su carácter de indicador común en las encuestas realizadas al efecto y su contribución en la descripción de la actitud ante la inmigración a partir de los resultados de una investigación previa (Valles, Cea e Izquierdo, 1999). A ella se remite para conocer las respuestas dadas a dichas preguntas en esta encuesta y en precedentes. Se mantiene la misma formulación y orden de aparición que en la encuesta de 1996, haciéndose referencia a variaciones en otras encuestas.

\section{Preguntas incluidas en el análisis}

P201: «Dígame, por favor, en una escala de 0 a 10, la simpatía que Ud. siente por los norteafricanos (marroquíes, etc.), teniendo en cuenta que 0 significa ninguna simpatía y 10 mucha simpatía».

P306: «A Ud. le preocuparía mucho, bastante, poco o nada que un hijo o una hija suyo se casara con un ciudadano de Marruecos u otro país norteafricano». Mucho (1) Bastante (2) Poco (3) Nada (4) No sabe (8) No contesta (9).

P4: «¿Hasta qué punto: mucho, bastante, poco o nada, le importaría a Ud. que sus hijos (si no los tiene, en caso de que los tuviera) compartieran en el colegio la misma clase con niños de familias inmigrantes extranjeras?». Mucho (1) Bastante (2) Poco (3) Nada (4) Depende de qué país fueran los niños (5) N.s. (8) N.c. (9). 
P506: «¿Hasta qué punto: mucho, bastante, poco o nada, le importaría a Ud. tener como vecinos a una familia de ciudadanos de Marruecos u otro país norteafricano?». Mucho (1) Bastante (2) Poco (3) Nada (4) N.s. (8) N.c. (9).

P606: "¿Y hasta qué punto: mucho, bastante, poco o nada, le importaría a Ud. tener como compañeros de trabajo a ciudadanos de Marruecos u otro país norteafricano?». Mucho (1) Bastante (2) Poco (3) Nada (4) N.s. (8) N.c. (9).

P7: «Como Ud. probablemente sabe, con la supresión de las fronteras entre los países de la Unión Europea (UE), podrán instalarse libremente en España trabajadores y profesionales del resto de los países de la UE. ¿Cómo valora Ud. esta medida?». Positivamente (1) Negativamente (2) Indiferente (3) N.s. (8) N.c. (9).

P8: «Y respecto a las personas de otros países que vienen a España solicitando refugio político, ¿qué cree Ud. que sería lo más adecuado?». Acogerlos sin restricciones (1) Acogerlos si se comprueba que están perseguidos (2) No acogerlos (3) N.s. (8) N.c (9).

P10: "Como Ud. sabe, todos los países desarrollados reciben inmigrantes. ¿Cree Ud. que, en términos generales, la inmigración es más bien positiva o más bien negativa para estos países?». Más bien positiva (1) Más bien negativa (2) Ni una cosa ni otra (No leer) (3) N.s. (8) N.c. (9).

P11: "Qué le parece a Ud. el número de personas procedentes de otros países que viven en España?». Son demasiados (1) Son bastantes, pero no demasiados (2) Son pocos (3) N.s. (8) N.c. (9).

P12: “¿Y cree Ud. que en los próximos años el número de extranjeros en España aumentará mucho, aumentará algo, se mantendrá igual o disminuirá?». Aumentará mucho (1) Aumentará algo (2) Se mantendrá igual (3) Disminuirá (4) N.s. (8) N.c. (9).

P15: «En relación a los inmigrantes que llegan a España, dígame, por favor, ¿̨cuál cree Ud. que es la intención de la mayoría de ellos?». Quedarse definitivamente a trabajar y a vivir en España (1) Permanecer aquí por un tiempo y después de ahorrar algún dinero regresar a sus países de origen (2) Permanecer aquí por un tiempo y luego trasladarse a otro país europeo (3) N.s. (8) N.c. (9).

P16: «Y, en su opinión, ¿̇cree que las leyes que regulan la entrada y permanencia de extranjeros en España son demasiado tolerantes, más bien tolerantes, correctas, más bien duras o demasiado duras?». Demasiado tolerantes (1) Más bien tolerantes (2) Correctas (3) Más bien duras (4) Demasiado duras (5) No conoce la legislación en materia de inmigración (6) N.s. (8) N.c. (9).

P17: "¿Considera Ud. que los derechos de los trabajadores extranjeros que viven en España deberían ampliarse, deberían dejarse como están o deberían reducirse?». Deberían ampliarse (1) Deberían dejarse como están (2) Deberían reducirse (3) N.s. (8) N.c. (9).

P18: "Como Ud. probablemente sabe, una parte de los inmigrantes, tanto en España como en otros países, se encuentra en situación ilegal. ¿Cree Ud. que hasta ahora las autoridades españolas han controlado mucho, bastante, poco o nada la estancia de extranjeros en España?». Mucho (1) Bastante (2) Poco (3) Nada (4) N.s. (8) N.c. (9).

P19: «Y, en general, ¿cree Ud. que se debería de tratar de regularizar la situación de los inmigrantes ilegales o, por el contrario, se les debería devolver a su país de origen?». Se debería regularizar su situación (1) Se les debería devolver a su país (2) N.s. (8) N.c. (9).

P21: «¿Qué política cree Ud. que sería la más adecuada con respecto a los trabajadores inmigrantes?». Facilitar la entrada de trabajadores inmigrantes (1) Facilitar la entrada sólo a aquellos que tengan un contrato de trabajo (2) Hacer muy difícil la entrada de trabajadores inmigrantes (3) Prohibir por completo la entrada de trabajadores inmigrantes (4) N.s. (8) N.c. (9).

P23: «El gobierno español ha establecido un cupo anual para la entrada de inmigrantes, esto es, un número máximo de extranjeros que pueden entrar a trabajar en el país cada año. En principio, ¿está Ud. muy de acuerdo, bastante de acuerdo, poco o nada de acuerdo con esta medida?». Muy de acuerdo (1) Bastante de acuerdo (2) Poco de acuerdo (3) Nada de acuerdo (4) N.s. (8) N.c. (9). 
P24: «Vamos a hablar ahora de las condiciones de vida de los inmigrantes en España. En general, ¿cómo diría Ud. que viven los inmigrantes en nuestro país?». Muy bien (1) Bastante bien (2) Bien (3) Mal (4) Bastante mal (5) Muy mal (6) N.s. (8) N.c. (9).

P26: «Y, por lo que Ud. sabe, ¿en España los trabajadores inmigrantes, en general, tienen o no mayores dificultades que el resto de los ciudadanos en su vida cotidiana?». Tienen mayores dificultades (1) No tienen mayores dificultades (2) N.s. (8) N.c. (9).

P27: «En cualquier caso, ¿cree Ud. que a los inmigrantes extranjeros, en general, se les debería dar o no facilidades para: traer a su familia a vivir con ellos, conseguir una vivienda digna, acceder (ellos y/o sus hijos) a la educación pública, tener asistencia sanitaria gratuita, obtener un puesto de trabajo en igualdad de condiciones con los españoles, constituir grupos o asociaciones para defender sus derechos, practicar su religión si lo desean?». Sí (1) No (2) N.s. (8) N.c. (9).

P28: “¿Y cree Ud. que toda persona extranjera que trabaje en España debería tener derecho a: cobrar el subsidio si se queda parado, votar en las elecciones municipales, votar en las elecciones generales, afiliarse a partidos políticos o sindicatos, obtener con el tiempo la nacionalidad española?». Sí (1) No (2) N.s. (8) N.c. (9).

P29: «Pensando en los trabajadores extranjeros en España que proceden de países menos desarrollados, dígame si está Ud. de acuerdo o en desacuerdo con las siguientes opiniones: los inmigrantes procedentes de países menos desarrollados desempeñan trabajos que los españoles no quieren hacer, al aceptar sueldos más bajos los trabajadores extranjeros hacen que bajen los salarios de los españoles, los inmigrantes quitan puestos de trabajo a los españoles, el aumento de los inmigrantes favorece el incremento de la delincuencia en nuestro país». De acuerdo (1) En desacuerdo (2) N.s. (8) N.c. (9).

P30: «A menudo, los inmigrantes que viven en España tienen una cultura, una lengua y unas condiciones distintas de los españoles. Con respecto a esto, dígame, por favor, con cuál de las siguientes frases está usted más de acuerdo». Aunque se queden a vivir en España y aprendan nuestra cultura es bueno que los inmigrantes mantengan también su lengua y sus costumbres (1) Si los inmigrantes quieren permanecer en España deben olvidar sus costumbres, aprender el idioma y aceptar las costumbres españolas (2) N.s. (8) N.c. (9).

P31: “¿Y cómo diría Ud. que los españoles, en general, tratan a los inmigrantes extranjeros?». Con desprecio (1) Con agresividad (2) Con desconfianza (3) Con indiferencia (4) Con amabilidad (5) Igual que si fueran españoles (6) N.s. (8) N.c. (9).

P33a: «¿Ha tenido relación de amistad con inmigrantes en España?. Sí (1) No (2) N.s. (8) N.c. (9).

P35: «Últimamente aparecen de vez en cuando noticias sobre ataques o agresiones violentas a inmigrantes extranjeros en España. En su opinión, ¿estas acciones violentas suponen un problema importante en nuestro país o, por el contrario, se trata por ahora de hechos aislados?». Suponen un problema importante (1) Se trata de hechos aislados (2) N.s. (8) N.c. (9).

P37: «En estos últimos años se está produciendo en algunos países europeos un cierto auge de partidos políticos de ideología racista que, como Le Pen en Francia, propugnan expulsar del país a ciertos colectivos por su raza o religión (negros, mahometanos, judíos, etc). ¿A $\mathrm{Vd}$. este auge le parece muy positivo, positivo, negativo o muy negativo?». Muy positivo (1) Positivo (2) Negativo (3) Muy negativo (4) N.s. (8) N.c. (9).

P38: “¿Cree Ud. que en España tendría mucha aceptación, bastante, poca o nada un partido político de ideología racista o xenófoba?». Mucha (1) Bastante (2) Poca (3) Ninguna (4) N.s. (8) N.c. (9).

De estas preguntas, en el barómetro de febrero de 2000 se excluyen once (P7, P8, P17, P18, P19, P23, P26, P27, P30, P37 y P38), y en el barómetro de febrero de 2001, dieciséis (P7, P8, P15, P16, P17, P18, P19, P23, P24, P26, P27, P28, P29, P35, P37 y P38). Las preguntas pueden a priori clasificarse en cinco grandes bloques: 
a) En primer lugar se sitúan preguntas relativas a «distancia social» —P306 (casar con marroquí), que indica un grado de intimidad máximo; y tres preguntas relativas a intimidad intermedia: P4 (colegio con marroquíes), P506 (vecino marroquí), P606 (trabajo con marroquíes)—. A ellas se suma la pregunta P201 (simpatía marroquí), que comparte con las anteriores la referencia expresa a un colectivo concreto de inmigrantes: los marroquíes. También cabe incluir otras preguntas que aluden al "afecto" sentido hacia los inmigrantes en general: P31 (trato a inmigrantes) y P33a (amistad con inmigrantes). Todas estas preguntas están, a su vez, incluidas en los barómetros de febrero de 2000 y de 2001.

Aunque en las tres encuestas del CIS aquí analizadas (al igual que en las encuestas de actitudes ante la inmigración de 1990, 1991, 1993 y 1995) se pregunta, además de por los norteafricanos (marroquíes...), por otros colectivos de inmigrantes extranjeros (europeos de la Unión Europea, latinoamericanos, rusos, norteamericanos, europeos de países del Este, portugueses, asiáticos, filipinos y resto de africanos), se escoge a los marroquíes por ser los peor valorados por la población española en todos los sondeos de opinión efectuados hasta la fecha ${ }^{8}$. A esta razón se suma el haber constatado que el "marroquí» es el inmigrante en quien más se piensa cuando se pregunta por la inmigración. A la pregunta "Cuando se habla de inmigrantes extranjeros que viven en España, ¿en quiénes piensa Ud. de manera inmediata» (P14), la mitad de los 2.493 encuestados en 1996 responde «marroquíes, moros». En la investigación previa de Valles, Cea e Izquierdo (1999) se trata con detenimiento el tratamiento mediático de la inmigración, por considerarlo un factor explicativo de la imagen estereotipada que se tiene de los inmigrantes en general, y de los marroquíes en particular. La antropóloga Ramírez Goicoechea (1996: 3-4) señala, igualmente, que «el inmigrante marroquí destaca como el más rechazado por la población autóctona». Y añade una interpretación que indica una pista explicativa más en esta línea indagatoria. Según esta autora, "el marroquí representa el epítome de la extranjería social y cultural para el ciudadano español. Es el banco de prueba de nuestra concepción liberal o no, del contacto entre grupos étnicos. Incluso más que en el caso de africanos de color».

La pregunta de "simpatía» se suma a cuatro concernientes a "distancia social», que tradicionalmente han actuado como indicadores de racismo. Desde la mirada antropológica también se ha escrito que «el matrimonio interétnico es una relación focal donde se manifiestan las valoraciones, gustos, prejuicios y distancia social, lengua y cultura. De ahí la alta significación que

${ }^{8}$ En las encuestas de CIRES/ASEP, al igual que en los estudios de CEMIRA, se incluye también a los gitanos y judíos, obteniendo los gitanos las peores valoraciones y siendo, en consecuencia, los más susceptibles a actitudes xenófobas y discriminatorias. Excepción hecha de la encuesta del CIRES de 1995, donde los "gitanos" alcanzan una valoración media ligeramente por encima de los «árabes y musulmanes", al ser sus puntuaciones medias respectivas 5,6 y 5,5. Pero, como el objetivo del presente estudio es la medición de las actitudes ante la «inmigración", no procede incluir la valoración de los gitanos ni de los judíos. 
otorgamos a cuestiones que se refieren al rechazo y recelo a casarse con extraños, siendo un sensible y extraordinario termómetro para medir la distancia social, la prevención y el prejuicio contra otros pueblos y etnias» (Calvo Buezas, 1990: 95). Pero, como se comprueba a continuación, las preguntas incluidas en este primer bloque son indicadores demasiado "directos», mostrando poca utilidad en la medición de las actitudes ante la inmigración. El encuestado puede adivinar la intención de la pregunta y modificar su respuesta para que ésta sea consonante con lo asumido en su grupo social de referencia. Además, como Newel (1993) advierte respecto a las preguntas hipotéticas, lo que el encuestado dice que podría hacer cuando se enfrenta a una situación dada no siempre expresa su conducta futura real. Existen preguntas que inevitablemente producen respuestas favorables por su deseabilidad social, mientras que otras provocan lo contrario por su indeseabilidad. O, como el mismo ASEP (1998: 34) reconoce: "Es ya habitual, en todos los estudio de xenofobia, racismo, exclusión social, o discriminación social en general, preguntar a los entrevistados qué harían si una hija suya se enamorase o quisiera casarse con un hombre perteneciente a uno de esos grupos sociales (...) los medios de comunicación han aleccionado a la opinión pública respecto a la interpretación de las respuestas, y como además muchos de los entrevistados no tienen hijas que puedan encontrarse en esa situación, les resulta fácil dar respuestas políticamente correctas». Este planteamiento cabe hacerlo extensible a otras preguntas similares.

b) En un segundo bloque están las preguntas relativas a política inmigratoria, que, como se muestra en el estudio de Valles, Cea e Izquierdo (1999), son a priori de mayor utilidad en la medición de las actitudes ante la inmigración, precisamente por ser indicadores de racismo menos directos que los precedentes. Incluye las preguntas P7 (supresión fronteras UE), P8 (refugiado político), P16 (leyes inmigración), P18 (control ilegales), P19 (regularizar ilegales), P21 (facilitar entrada inmigrantes) y P23 (cupo inmigrantes). Pero, a diferencia del bloque anterior, de estas preguntas sólo se mantienen, lamentablemente, dos en el barómetro de febrero de 2000 (P16 y P21) y una en el de febrero de 2001 (P21).

Las encuestas de CIRES/ASEP sí incluyen una pregunta relativa a la "regularización» de los inmigrantes ilegales, aunque ofreciendo más opciones de respuesta que en las encuestas del CIS: regularizar su situación, tengan o no trabajo; regularizar su situación, si tienen trabajo actualmente; darles un período de tres meses para encontrar trabajo y, en caso contrario, devolverles a su país de origen; expulsarles de España. Ello permite una mayor concreción en la respuesta. Además, se pide a los encuestados que valoren el "cupo" de trabajadores extranjeros prefijado por el gobierno en la política de cuotas. A diferencia de la pregunta formulada en la encuesta del CIS de 1996 (P23), en las de CIRES/ASEP se menciona, cada año, la cuota fijada por el gobierno, lo que es de gran ayuda en dicha valoración. Esta última pregunta se complementa con otra en la que se solicita al encuestado que se posicione ante la limitación de la 
entrada en España de inmigrantes procedentes de países menos desarrollados (muy partidario, partidario, contrario y muy contrario) ${ }^{9}$.

En la investigación de Calvo Buezas (2000), circunscrita a estudiantes de primaria y secundaria, también se incluye una pregunta relativa a la entrada de trabajadores extranjeros, obteniéndose, como en el Eurobarómetro de 1997, una mayor declaración de actitudes contrarias a su entrada que en las encuestas del CIS ${ }^{10}$.

c) Un tercer bloque agrupa preguntas que aluden a una dimensión básica del llamado "racismo moderno": los derechos de los inmigrantes y su equiparación con los trabajadores autóctonos. A saber, P17 (ampliación derechos), P27 (traer a su familia, vivienda digna, educación pública, asistencia sanitaria gratuita, trabajo en igualdad, constituir asociaciones, practicar su religión), P28 (cobrar paro, votar elecciones municipales, votar elecciones generales, afiliarse a partidos o sindicatos, obtener la nacionalidad) y P30 (mantener sus costumbres). En el barómetro de febrero de 2000 sólo se consideran los items incluidos en P28, y en el barómetro de febrero de 2001, únicamente los habidos en P30. La variabilidad de las preguntas es pequeña debido a que en general hacen referencia a propuestas que suscitan gran deseabilidad social, siendo la respuesta «sí» mayoritaria en todas las actuaciones dirigidas a la mejora de las condiciones de vida de los inmigrantes extranjeros. La mayor reticencia se manifiesta ante la posibilidad de que puedan votar en las elecciones generales $(60 \%$ en 1996 y $62 \%$ en 2000) y municipales (65\% en ambos sondeos de opinión) y, algo menos, cuando se contempla su afiliación a partidos políticos y organizaciones sindicales (el sí agrupa al 70\% de las respuestas en ambas fechas).

En las encuestas de CIRES/ASEP también se pulsa la opinión sobre una serie de derechos (al desempleo, una vivienda digna, asistencia sanitaria pública, educación gratuita para sus hijos y para su cónyuge, cursos de español y formación profesional) cuya concesión se plantea en el caso de los inmigrantes regularizados como de los ilegales (obteniéndose respecto a estos últimos un grado de aceptación menor). A estas cuestiones se añaden dos específicas: una, no deben tener acceso a ninguna prestación social; y dos, deben tener acceso sólo a las prestaciones de emergencia por razones humanitarias.

${ }^{9}$ El 53\% de los encuestados en 1996 y el 46\% en 1998 se muestran partidarios de dicha limitación (un 8 y un 6\%, respectivamente, declaran ser muy partidarios). En el Eurobarómetro de 1997, el $61 \%$ de los españoles encuestados afirma que «todos los inmigrantes ilegales no europeos, sin excepción, deben ser enviados de nuevo a su país de origen». Respuesta contraria a la obtenida en junio de 1996 por el CIS, donde el 66\% de los 2.493 encuestados dice ser favorable a la regularización de los inmigrantes ilegales y sólo un $21 \%$ prefiere que se les devuelva a su país de origen.

${ }^{10} \mathrm{El}$ formato de la pregunta es distinto, lo que no significa que sea mejor. Al encuestado se le pide que escoja una de las siguientes opciones: "En España hay ya demasiados trabajadores inmigrantes extranjeros y habría que expulsar a algunos a su país de origen; en España hay los suficientes trabajadores extranjeros y hay que impedir que entren más pero no expulsar a los que ya están dentro; en España hay todavía pocos extranjeros y debemos acoger a bastantes más». A los que optan por la última respuesta se les llama «hospitalarios» (el 15\% de los 6.000 encuestados) y a los que eligen la primera (11\%) se les considera claramente «xenófobos». 
La cuestión del reagrupamiento familiar se ha abordado de modo diferente por parte del CIS y del CIRES/ASEP. Según el primer instituto de opinión pública, en 1996 la gran mayoría de los españoles (81\%) se muestra favorable a que los inmigrantes puedan "traer a su familia a vivir con ellos». En las encuestas del CIRES/ASEP, en cambio, se opta por ofrecer a los encuestados dos proyectos migratorios dispares: 1) El del asentamiento definitivo («que los inmigrantes vengan a España con sus familiares y se asienten para siempre»), en el que no habría reagrupamiento familiar como tal, pues el inmigrante viene ya con su familia. Ante este supuesto de llegada con la familia y "para siempre», la respuesta favorable se contrae en 1996 al 38\% y aumenta al 48\% en 1998. En cualquier caso, lejos del resultado producido por el CIS. 2) El proyecto migratorio individual (sólo el trabajador), de temporada y con retorno. Esto es, "que los inmigrantes vengan una temporada sin sus familiares y que luego regresen a su país». Esta segunda opción atrae las respuestas del 39\% de los encuestados en 1996 y del 33\% en 1998. Datos tampoco comparables con los obtenidos en la encuesta del CIS, al incluir en una misma proposición dos temas diferentes: el reagrupamiento familiar y la permanencia en España, que suscitan respuestas no necesariamente concordantes ${ }^{11}$.

d) Un cuarto grupo de items incluye los referidos a la imagen o percepción de la inmigración: P10 (valoración inmigración), P11 (número de inmigrantes), P12 (aumentará número de inmigrantes), P15 (quedarse en España), P24 (condiciones vida inmigrantes), P26 (dificultades inmigrantes) y P29 (trabajos no cualificados, bajan salarios, quitan trabajo, aumentan delincuencia). En el barómetro de febrero de 2000 se excluye la pregunta P26. En febrero de 2001 tan sólo se consideran tres preguntas: P10, P11 y P12; el resto se omite. A estas tres preguntas se añade una que complementa a P10: «¿Cree Ud. que en España se necesitan trabajadores inmigrantes?» (el 60\% de los encuestados afirma sí y el $28 \%$ no).

La valoración de los efectos de la inmigración para la sociedad de recepción es un integrante habitual en las encuestas que venimos analizando. En las encuestas de CIRES/ASEP se pide a los encuestados que evalúen los efectos de la inmigración para nuestra cultura, con las siguientes opciones de respuesta: muy buena, buena, ni buena ni mala, mala y muy mala. En el Eurobarómetro de 1997 el verbatim de la pregunta era: "Hablando en términos generales, ¿tú piensas que tu país se beneficia de los inmigrantes no europeos o, por el contrario, piensas que tu país estaría mejor sin ellos?».

${ }^{11}$ Adviértase que en los supuestos migratorios planteados por CIRES/ASEP se dejan fuera las experiencias o planes donde se combinan el reagrupamiento familiar con el retorno en el medio o largo plazo. Además, dichos supuestos (aun siendo de gran interés prospectivo), en tanto preguntas de encuesta, rompen con el principio general de una idea, una pregunta. Es decir, las opciones de respuesta incluyen dos cuestiones a la vez (carácter familiar o individual de la migración y su carácter definitivo o temporal). Lo cual dificulta la interpretación de las respuestas obtenidas (Cea, 1996). 
También es habitual incluir una pregunta relativa al número de inmigrantes y su pronóstico. La percepción del número de inmigrantes se considera una cuestión crucial «porque una imagen distorsionada y agigantada puede contribuir a un estereotipo falso, que incita y sustenta la xenofobia» (Calvo Buezas, 2000: 127). En cambio, los items relativos a la intencionalidad del inmigrante extranjero y a sus condiciones de vida son menos comunes. Asimismo, es frecuente incluir aquellas cuestiones que más rechazo suele suscitar la presencia de inmigrantes extranjeros por parte de la sociedad receptora: el empleo y el incremento de la delincuencia. "La cuestión laboral es uno de los argumentos más presentes en el discurso contrario a la inmigración. El trabajador del país receptor, especialmente si disfruta de menor estabilidad en el empleo, ve en el inmigrante un peligro para su situación laboral» (Blasco, 1992: 61). Además, «la llegada de extranjeros inmigrantes económicos, legales o clandestinos, supone un incremento en la competencia por la captación de los recursos destinados a los estratos más bajos de la sociedad española» (Gaviria, 1992: 134). Por otra parte, se comprueba que las drogas y la delincuencia son dos falsos y peligrosos estereotipos que se asocian a la inmigración (Valles, Cea e Izquierdo, 1999; Calvo Buezas, 2000).

e) Un último bloque abarca preguntas que aluden a conductas manifiestas de rechazo ante la presencia de inmigrantes extranjeros, ya en forma de ataques o agresiones violentas: P35 (agresiones inmigrantes), ya de apoyo a partidos políticos de ideología racista: P37 (auge partido racista) y P38 (aceptación partido racista). Estas dos últimas preguntas no se incluyen en los barómetros de febrero de 2000 ni de 2001.

En las encuestas de CIRES/ASEP se pide que se evalúe el racismo o xenofobia en España en comparación con otros países europeos. Además, se solicita que se elija uno, de una serie de motivos sugeridos, que más explica que en España seamos menos racistas: uno, "España ha sido históricamente un país abierto al exterior en el que no hay rechazo a los de fuera» (52\% en 1996 y $67 \%$ en 1998); dos, «En España hay todavía muchos menos inmigrantes que en otros países europeos y surgen menos conflictos» (40\% en 1996 y $27 \%$ en 1998). Aunque, tal vez, hubiera sido más conveniente haber dejado la pregunta abierta, para así abrir más el abanico de posibilidades al respecto y poder captar los motivos espontáneos.

En el Eurobarómetro de 1997 se pide directamente al entrevistado que se autoposicione como «nada», «algo», «bastante» o "muy racista». En una encuesta del CIS a jóvenes (Mateos y Moral, 2000) se indaga igualmente en estas cuestiones. Se pregunta por la aceptación en general que tendría un partido de ideología racista o xenófoba en España (mucha, bastante, poca y ninguna). Esta pregunta se complementa con otra más directa: «Y si en España existiera un partido de este tipo, ¿estarías dispuesto a votarle?». Además, en vez de preguntar si los ataques o agresiones violentas a inmigrantes extranjeros suponen un problema importante en nuestro país o se trata, por el contrario, de 
hechos aislados, se pregunta directamente por el apoyo personal concedido a estas conductas agresivas. La pregunta dice así: «Últimamente están apareciendo en algunos países europeos grupos que promueven acciones discriminatorias, incluso violentas, contra inmigrantes y minorías étnicas como negros, musulmanes, judíos, gitanos, etc. ¿Podría decirme, por favor, si dichas acciones las aprueba por completo, las aprueba hasta cierto punto, indiferente (no leer), las desaprueba hasta cierto punto y las desaprueba completamente?». Sorprende que un $15 \%$ de los 2.434 jóvenes encuestados en 1997 declare abiertamente un grado determinado de aprobación de dichas conductas, aun sabiendo que son actuaciones que la sociedad actual penaliza. Ello revierte positivamente en esta pregunta como actitud manifiesta contraria a la inmigración exterior.

En la encuesta de CEMIRA (Calvo Buezas, 2000) también se optó por formular una pregunta directa ( ¿ंTú, si tuvieras edad y ocasión, votarías por un partido político, como el de Le Pen en Francia, que se propusiera echar de España a los trabajadores inmigrantes marroquíes y a los negros africanos?»), obteniendo un $10 \%$ de respuestas afirmativas.

\section{LA EFECTIVIDAD DE LOS INDICADORES}

En primer lugar, se ha procedido a realizar un análisis factorial de componentes principales con todas las variables, con el objetivo de descubrir si dichas variables comparten alguna estructura latente. Esta serie menor de variables latentes ha de caracterizarse por aglutinar variables bastante correlacionadas entre sí y escasamente correlacionadas con las que forman otra estructura latente o dimensión del concepto que se analiza: racismo.

Para su aplicación se ha procedido a la transformación en ficticias de las variables nominales y a la recodificación de las variables ordinales que propicia la correspondencia entre el código numérico y la cualidad que expresa (véase Cea, 2002: 18-24). Además, se ha procedido a la estandarización previa de las variables para facilitar su comparabilidad. El elevado tamaño muestral $(n=2.493)$ posibilita la obtención de estimaciones fiables de los coeficientes de correlación. El modelo se obtiene a partir de la matriz de correlaciones. Su determinante (2,255E-06), al igual que la medida de adecuación muestral de Kaiser-MeyerOlkin $(0,919)$ y la prueba de esfericidad de Bartlett $\left(\chi^{2}=10590,57\right.$ g.l. $=820$ significación $=0,000)$, indican que el análisis de componentes principales es factible, pues existe la suficiente varianza común entre las variables observadas para permitir su agrupación en combinaciones lineales de variables correlacionadas.

La matriz factorial se rota mediante el procedimiento de rotación ortogonal varimax. De este modo, se busca su mayor simplicidad: haciendo máxima la varianza de los coeficientes factoriales cuadrados en cada componente principal y obteniendo dimensiones latentes no correlacionadas entre sí. Es decir, que los indicadores midan dimensiones diferentes en los datos. La tabla A resume la composición de los diez componentes obtenidos tras la aplicación 


\section{TABLA A}

Composición de los componentes principales tras la rotación varimax

\begin{tabular}{|c|c|c|c|}
\hline 1 Derechos sociales & & 2 Derechos de ciudadanía & \\
\hline Educación pública .......................... & 0,824 & 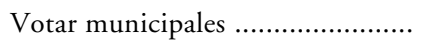 & 0,879 \\
\hline 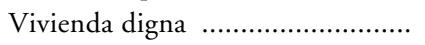 & 0,770 & Votar elecciones generales .............. & 0,877 \\
\hline Asistencia sanitaria ......................... & 0,747 & Afiliarse a partidos políticos ......... & 0,780 \\
\hline Practicar su religión ........................ & 0,702 & Obtener la nacionalidad ................ & 0,491 \\
\hline Trabajo en igualdad ........................ & 0,672 & & \\
\hline Constituir asociaciones ................... & 0,669 & & \\
\hline Traer a su familia ............................ & 0,666 & & \\
\hline 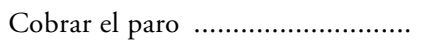 & 0,463 & & \\
\hline Mantener sus costumbres ............... & 0,286 & & \\
\hline
\end{tabular}

3 Sociabilidad con marroquies

Vecino marroquí

0,822

Compañero de trabajo marroquí ..

Casar con marroquí

Colegio con inmigrantes

Simpatía hacia marroquíes

\section{Politica inmigratoria}

$0,788 \quad$ Supresión fronteras UE ................ 0,606

$0,708 \quad$ Refugiado político ...................... 0,519

0,595 Control inmigración .................. 0,509

-0,492 Regularizar inmigrantes .............. 0,455

Leyes inmigración ..................... 0,452

Facilitar entrada a inmigrantes .... 0,429

Número de inmigrantes .............. $\quad-0,368$

\section{Imagen tópica negativa del inmigrante}

Bajan salarios

0,751

0,750

Quitan trabajo

0,586

\section{Discriminación étnica o de la alteridad}

Condiciones de vida del inmigrante .. $\quad-0,699$

Dificultades de los inmigrantes ... 0,582

Trabajos no cualificados ............. 0,536

Ampliación derechos .................. 0,456

\section{Partido racista}

Aceptación partido racista

Partido racista
0,766

0,446

\section{Aceptación del inmigrante}

Amistad con inmigrantes ........... 0,668

Aumentará número de inmigrantes.. $\quad-0,583$

Cupo inmigrantes

$-0,274$

10 Temor al asentamiento de inmigrantes

9 Violencia contra inmigrantes

Problema agresiones inmigrantes..

0,817
0,652

$-0,593$ 
del criterio habitual de autovalores $\geq 1,00$ (al menos ha de explicar la varianza total de una variable $)^{12}$. Los componentes figuran en su orden de aparición en la matriz rotada, acompañados de la etiqueta asignada por mi parte para su denominación. Se ha intentado que el nombre dado al componente refleje el significado de las variables que en él pesan más y que sintetice su contenido común. Las variables aparecen acompañadas de sus coeficientes factoriales, cuya magnitud señala lo que caracteriza a cada componente ${ }^{13}$.

La varianza total explicada por la combinación de las 41 variables empíricas en 10 componentes principales (o dimensiones latentes) es 53,956\%. Como es habitual, la proporción es mayor en los primeros componentes y menor en los últimos $(11,56,7,27,7,11,6,78,5,48,4,20,2,98,2,96,2,84$ y $2,76 \%$, respectivamente). Los últimos componentes también se caracterizan por ser bipolares (incluyen coeficientes positivos y negativos). Tras la solución factorial, las variables cuya variabilidad queda menos explicada, a decir por sus comunalidades finales (o proporción de varianza de la variable que es explicada por los componentes), son: mantener sus costumbres $(0,287)$, cupo de inmigrantes $(0,314)$, refugiado político $(0,384)$ y trabajos no cualificados $(0,388)$.

La efectividad de los componentes obtenidos se comprueba mediante un análisis discriminante. Ello exige el previo cálculo de las puntuaciones factoriales para que en la representación de cada dimensión latente intervengan todas las variables con coeficiente factorial significativo. Se aplica el método de Anderson-Rubin porque propicia la obtención de puntuaciones factoriales no correlacionadas ${ }^{14}$.

En el análisis discriminante actúa como variable dependiente la clasificación en tres grupos obtenida mediante la realización previa de un análisis de conglomerados $k$-medias, en consonancia con la actitud declarada ante la inmigración. $\mathrm{La}$ tabla $\mathrm{B}$ incluye los centros de los conglomerados finales ${ }^{15}$, que describen la composición de cada grupo. Al estar las variables estandarizadas, su interpretación se hace en unidades de desviación típica por encima (signo positivo) o por debajo (signo negativo) de la media. Los grupos más polares son el conglomerado 2 (los más favorables a la inmigración) y el conglomerado 3 (los más reacios). Los clasificados en el conglomerado 1 se sitúan entre ambos extremos. El 67\% de los 2.493 encuestados queda clasificado en el conglomerado 2; en el conglomerado 1, el $27 \%$, y sólo un $6 \%$ en el conglomerado 3. De ello se deduce que los items incluidos en la encuesta aquí analizada sólo logran identificar a un $6 \%$ de sujetos reacios a la inmigración. Hecho éste a destacar.

${ }^{12}$ El gráfico de sedimentación indica, no obstante, la existencia clara de cinco componentes principales. Esta clasificación se descarta porque supone una reducción en varianza total explicada a $41 \%$ y una peor composición de los componentes, que quedan peor delimitados en su significado lógico-sustantivo.

${ }^{13}$ Su valor expresa la correlación de cada variable observada con cada componente y su signo la dirección de dicha relación: positiva o negativa.

14 Téngase presente que el análisis discriminante se ve negativamente afectado por correlaciones elevadas entre las variables independientes. Dicha correlación también se trató de obviar aplicando una rotación ortogonal de los ejes factoriales.

${ }_{15}$ Definidos por los valores promedio de las variables en los casos que componen el conglomerado. 


\section{TABLA B}

\section{Centros de los conglomerados finales}

\begin{tabular}{|c|c|c|c|}
\hline \multirow[b]{2}{*}{ Variables } & \multicolumn{3}{|c|}{ Conglomerados } \\
\hline & 1 & 2 & 3 \\
\hline 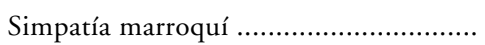 & $-0,5495$ & 0,3158 & $-1,1566$ \\
\hline Casar con marroquí ................................ & 0,6359 & $-0,3479$ & 1,1425 \\
\hline Colegio con inmigrantes ........................ & 0,1406 & $-0,1861$ & 1,5587 \\
\hline 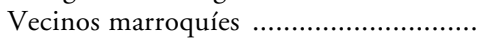 & 0,3421 & $-0,2756$ & 1,6534 \\
\hline Compañero trabajo marroquí ................ & 0,3031 & $-0,2729$ & 1,8734 \\
\hline 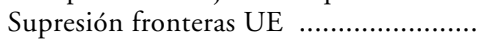 & $-0,5474$ & 0,2921 & $-0,9518$ \\
\hline Refugiado político & $-0,4869$ & 0,2771 & $-0,9342$ \\
\hline 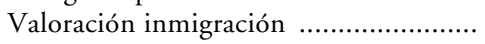 & $-0,5599$ & 0,2891 & $-0,7806$ \\
\hline Número de inmigrantes ............................. & 0,5357 & $-0,2846$ & 0,6723 \\
\hline Aumentará número inmigrantes ............ & 0,1783 & $-0,1083$ & 0,4042 \\
\hline Intención quedarse & 0,1382 & $-0,0603$ & 0,0562 \\
\hline 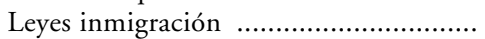 & $-0,5303$ & 0,3000 & $-0,8038$ \\
\hline 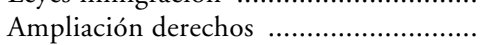 & $-0,4979$ & 0,2591 & $-0,7556$ \\
\hline Control inmigración ................................ & $-0,3153$ & 0,1904 & $-0,6319$ \\
\hline Regularizar inmigrantes ......................... & $-0,5349$ & 0,3152 & $-1,2397$ \\
\hline Facilitar entrada inmigrantes .................. & $-0,4643$ & 0,3158 & $-1,4615$ \\
\hline 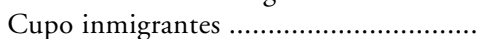 & 0,2571 & $-0,1069$ & $-0,0235$ \\
\hline Condiciones vida inmigrantes ................. & 0,1862 & $-0,1224$ & 0,6055 \\
\hline 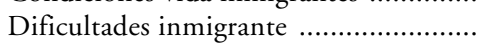 & $-0,1505$ & 0,1010 & $-0,5518$ \\
\hline Traer a su familia & $-0,2491$ & 0,2790 & $-2,4613$ \\
\hline 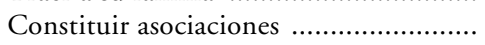 & $-0,2626$ & 0,2793 & $-2,4685$ \\
\hline Votar elecciones generales ........................ & $-0,7821$ & 0,4064 & $-1,1915$ \\
\hline Afiliarse partidos políticos ..................... & $-0,7270$ & 0,3868 & $-1,5105$ \\
\hline Obtener la nacionalidad ......................... & $-0,3093$ & 0,2796 & $-2,1984$ \\
\hline Trabajos no cualificados ........................... & $-0,1715$ & 0,1149 & $-0,5450$ \\
\hline Bajan salarios & 0,4292 & $-0,2174$ & 0,4388 \\
\hline Quitan trabajo & 0,5658 & $-0,3037$ & 0,6385 \\
\hline Aumentan delincuencia .......................... & 0,4943 & $-0,2669$ & 0,5858 \\
\hline Mantener sus costumbres .......................... & $-0,3681$ & 0,2262 & $-1,0618$ \\
\hline 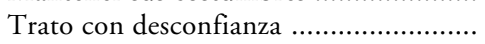 & 0,0907 & $-0,0281$ & $-0,0905$ \\
\hline Amistad con inmigrantes ........................ & $-0,3606$ & 0,1205 & $-0,2075$ \\
\hline Problema agresiones inmigrantes .......... & $-0,0993$ & 0,0539 & $-0,1930$ \\
\hline Partido racista & 0,3837 & $-0,2066$ & 0,9121 \\
\hline Aceptación partido racista ....................... & 0,0432 & $-0,0422$ & 0,3638 \\
\hline 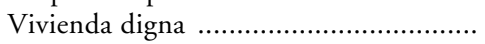 & $-0,0539$ & 0,2313 & $-2,8417$ \\
\hline Educación pública ................................ & 0,1716 & 0,1932 & $-3,4760$ \\
\hline Asistencia sanitaria .................................. & $-0,0186$ & 0,2139 & $-2,6821$ \\
\hline Trabajo en igualdad .................................. & $-0,2064$ & 0,2830 & $-2,6650$ \\
\hline Practicar su religión ................................ & 0,0686 & 0,1781 & $-2,8096$ \\
\hline 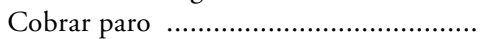 & $-0,1708$ & 0,2378 & $-2,1762$ \\
\hline Votar municipales ................................... & $-0,7880$ & 0,4140 & $-1,3037$ \\
\hline Número de casos .. & 674 & 1.676 & 143 \\
\hline
\end{tabular}


Las pruebas $\mathrm{F}$ realizadas confirman, además, que las 41 variables analizadas se muestran «relevantes» en dicha clasificación. La variable de menor significatividad es "trato con desconfianza» $(0,027)$, aunque se sitúa por debajo del nivel comúnmente establecido de 0,05. Las demás variables presentan la plena significatividad $(0,000)$ en el análisis de la varianza (anova) realizado.

Partiendo de dicha agrupación, a continuación se realiza un análisis discriminante con el objetivo de comprobar qué combinación lineal de variables independientes (los diez componentes principales antes obtenidos) maximiza la diferencia entre estos tres grupos. A efectos de validación de los resultados del análisis, se divide aleatoriamente la muestra en dos submuestras: la muestra de análisis (1.256 casos) y la de validación (1.229 casos), destinada a la comprobación de la validez de los resultados.

Primero, se comprueba si «realmente» las medias de las variables independientes difieren entre los tres grupos en el plano analítico univariable mediante la lambda de Wilks y la razón $F$, calculado a partir de la $D^{2}$ de Mahalanobis. En la tabla $\mathrm{C}$ puede observarse que los seis primeros componentes (o dimensiones latentes) son los que contribuyen significativamente a la diferenciación de los tres grupos en ambas submuestras, al apreciarse diferencias significativas entre sus medias. De manera especial, los items relativos a derechos sociales, que presentan el valor lambda más bajo y el valor $F$ más elevado. Esta apreciación se corrobora tras la realización del análisis discriminante propiamente dicho.

Tras la aplicación de un procedimiento iterativo secuencial de inclusión y eliminación de variables predictoras de acuerdo con su poder discriminatorio, se confirma que son las seis primeras variables latentes las que contribuyen a la diferenciación entre los tres grupos de una forma estadísticamente significativa, como muestra la tabla $\mathrm{D}$. Las variables figuran ordenadas según el paso en que fueron incorporadas al modelo. La variable elegida en cada paso es aquella que cumple la doble condición de tener el valor lambda más pequeño (próximo a 0$)$ y el valor $F$ más elevado. Ambos requisitos se relacionan con variables cuyas medias difieren bastante en los tres grupos provocando, a su vez, una elevada cohesividad intragrupal (entre los integrantes del mismo grupo).

De la comparación de los grupos por pares, mediante el estadístico $F$ (que es proporcional a la $D^{2}$ de Mahalanobis, permitiendo su uso como medida de la distancia entre cada par de grupos), se obtiene que los grupos más próximos son el 1 (los intermedios) y el 2 (los favorables a la inmigración), al ser su valor $F$ el más bajo $(36,204)$. En cambio, los más alejados son los grupos 2 y 3 (los reacios), al obtener el valor $F$ más elevado $(131,609$, también con plena significatividad).

Al haber tres grupos y diez variables predictoras, son dos las funciones discriminantes derivadas. En la tabla E puede verse que, como es habitual, la primera función está compuesta por la combinación lineal de variables que más logra diferenciar entre los grupos (un autovalor de 5,762, que se traduce en un $82,8 \%$ de varianza explicada de la variable dependiente); si bien ambas funciones son útiles en la explicación de las diferencias grupales, al ser sus correlacio- 


\section{TABLA C}

Pruebas de igualdad en las medias de los grupos

\begin{tabular}{|c|c|c|c|c|c|c|c|c|c|c|}
\hline \multirow[b]{2}{*}{ Dimensiones } & \multicolumn{5}{|c|}{ Muestra de análisis } & \multicolumn{5}{|c|}{ Muestra de validación } \\
\hline & $\begin{array}{l}\text { Lambda } \\
\text { de Wilks }\end{array}$ & $F$ & GL1 & GL2 & Sig. & $\begin{array}{l}\text { Lambda } \\
\text { de Wilks }\end{array}$ & $F$ & GL1 & $G L 2$ & Sig. \\
\hline Derechos sociales .......................... & 0,236 & 234,297 & 2 & 145 & 0,000 & 0,260 & 200,234 & 2 & 141 & 0,000 \\
\hline Derechos de ciudadanía ............ & 0,765 & 22,278 & 2 & 145 & 0,000 & 0,780 & 19,876 & 2 & 141 & 0,000 \\
\hline Sociabilidad con marroquíes .... & 0,895 & 8,515 & 2 & 145 & 0,000 & 0,831 & 14,323 & 2 & 141 & 0,000 \\
\hline Política inmigratoria .................... & 0,793 & 18,874 & 2 & 145 & 0,000 & 0,830 & 14,391 & 2 & 141 & 0,000 \\
\hline Imagen tópica negativa $\ldots \ldots \ldots \ldots \ldots$ & 0,923 & 6,040 & 2 & 145 & 0,003 & 0,926 & 5,620 & 2 & 141 & 0,004 \\
\hline Discriminación étnica .................. & 0,916 & 6,688 & 2 & 145 & 0,002 & 0,876 & 10,022 & 2 & 141 & 0,000 \\
\hline Partido racista ............................... & 0,967 & 2,455 & 2 & 145 & 0,089 & 0,994 & 0,398 & 2 & 141 & 0,673 \\
\hline Aceptación del inmigrante ........ & 0,973 & 1,976 & 2 & 145 & 0,142 & 0,995 & 0,321 & 2 & 141 & 0,726 \\
\hline Violencia contra inmigrantes .... & 0,988 & 0,873 & 2 & 145 & 0,420 & 0,987 & 0,941 & 2 & 141 & 0,393 \\
\hline Temor al asentamiento .............. & 0,940 & 4,590 & 2 & 145 & 0,012 & 0,959 & 3,027 & 2 & 141 & 0,052 \\
\hline
\end{tabular}

Adviértase que los casos válidos que participan en la derivación de las funciones discriminantes se reducen a 148 (en la muestra de análisis) y 144 (en la de validación), debido a que se ha aplicado, a su vez, un procedimiento de validación cruzada. Los casos excluidos lo son porque al menos una variable predictora está perdida. Después, en la clasificación participarán todos los casos que componen la muestra. 


\section{TABLA D}

Variables introducidas/eliminadas en cada paso ${ }^{\mathrm{a}, \mathrm{b}, \mathrm{c}, \mathrm{d}}$

\begin{tabular}{|c|c|c|c|c|c|c|c|}
\hline \multirow[b]{2}{*}{ Paso } & \multirow[b]{2}{*}{ Dimensiones } & \multicolumn{3}{|c|}{ Muestra de análisis } & \multicolumn{3}{|c|}{ Muestra de validación } \\
\hline & & $\begin{array}{l}\text { Lambda } \\
\text { de Wilks }\end{array}$ & $F$ & Sig. & $\begin{array}{l}\text { Lambda } \\
\text { de Wilks }\end{array}$ & $F$ & Sig. \\
\hline 1 & Derechos sociales ...... & 0,236 & 234,297 & 0,000 & 0,260 & 200,234 & 0,000 \\
\hline 2 & Derechos de ciudadanía & 0,176 & 99,759 & 0,000 & 0,198 & 87,507 & 0,000 \\
\hline 3 & 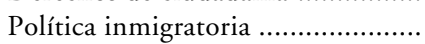 & 0,115 & 92,988 & 0,000 & 0,152 & 72,445 & 0,000 \\
\hline 4 & Sociabilidad con marroquíes .......... & 0,093 & 81,047 & 0,000 & 0,110 & 69,680 & 0,000 \\
\hline 5 & Imagen tópica negativa ...................... & 0,073 & 76,332 & 0,000 & 0,091 & 63,333 & 0,000 \\
\hline 6 & Discriminación étnica $\ldots \ldots \ldots \ldots \ldots \ldots \ldots . . . . . . . . .$. & 0,067 & 66,669 & 0,000 & 0,081 & 56,781 & 0,000 \\
\hline
\end{tabular}

En cada paso se introduce la variable que minimiza la lambda de Wilks global.

a El número máximo de pasos es 20.

b La $F$ parcial mínima para entrar es 3,84.

La $F$ parcial máxima para eliminar es 2,71.

d El nivel de $F$, la tolerancia o el VIN son insuficientes para continuar los cálculos.

\section{TABLA E}

Relevancia de las funciones discriminantes canónicas

\begin{tabular}{|c|c|c|c|c|c|c|c|c|}
\hline \multirow[b]{3}{*}{ Función } & \multicolumn{4}{|c|}{ Muestra de análisis } & \multicolumn{4}{|c|}{ Muestra de validación } \\
\hline & \multicolumn{4}{|c|}{ Autovalores } & \multicolumn{4}{|c|}{ Autovalores } \\
\hline & Autovalor & $\begin{array}{c}\% \text { de } \\
\text { varianza }\end{array}$ & $\begin{array}{c}\% \text { de } \\
\text { varianza } \\
\text { acumulado }\end{array}$ & $\begin{array}{l}\text { Corre- } \\
\text { lación } \\
\text { canónica }\end{array}$ & Autovalor & $\begin{array}{c}\% \text { de } \\
\text { varianza }\end{array}$ & $\begin{array}{c}\% \text { de } \\
\text { varianza } \\
\text { acumulado }\end{array}$ & $\begin{array}{c}\text { Corre- } \\
\text { lación } \\
\text { canónica }\end{array}$ \\
\hline 1 & $5,762^{*}$ & 82,8 & 82,8 & 0,923 & $4,456^{*}$ & 78,1 & 78,1 & 0,904 \\
\hline \multirow[t]{2}{*}{2} & $1,200^{*}$ & 17,2 & 100,0 & 0,739 & $1,252^{*}$ & 21,9 & 100,0 & 0,746 \\
\hline & \multicolumn{4}{|c|}{ Lambda de Wilks } & \multicolumn{4}{|c|}{ Lambda de Wilks } \\
\hline $\begin{array}{l}\text { Contraste } \\
\text { funciones }\end{array}$ & $\begin{array}{l}\text { Lambda } \\
\text { de Wilks }\end{array}$ & $\begin{array}{c}\text { Chi- } \\
\text { cuadrado }\end{array}$ & $G L$ & Sig. & $\begin{array}{l}\text { Lambda } \\
\text { de Wilks }\end{array}$ & $\begin{array}{c}\text { Chi- } \\
\text { cuadrado }\end{array}$ & $G L$ & Sig. \\
\hline 1 a la 2 & 0,067 & 384,736 & 12 & 0,000 & 0,081 & 347,416 & 12 & 0,000 \\
\hline 2 & 0,454 & 112,377 & 5 & 0,000 & 0,444 & 112,409 & 5 & 0,000 \\
\hline
\end{tabular}

\footnotetext{
* Se han empleado las dos primeras funciones discriminantes canónicas en el análisis.
} 
nes canónicas muy elevadas. Además, son estadísticamente significativas, a decir por el contraste de las funciones realizado mediante lambda de Wilks y chi-cuadrado. Tan sólo el 6,7\% de la varianza de la variable dependiente (la diferenciación entre los grupos) "no» es explicado por las funciones discriminantes. En suma, con ambas funciones se alcanza una discriminación entre los grupos casi "perfecta", al ocasionar mucha variabilidad entre los grupos y escasa entre sus integrantes. La prueba chi-cuadrado confirma que las diferencias en las medias grupales no se deben a errores de muestreo, siendo, por el contrario, estadísticamente significativas.

Las variables que forman cada función se exponen en la tabla F. Tomando el indice de potencialidad compuesto ${ }^{16}$ como medida de síntesis, se obtiene que las variables latentes o componentes que más discriminan son precisamente aquellas que primero forman el modelo discriminante: las referidas a derechos sociales, derechos civiles y política inmigratoria. Las variables relativas a derechos sociales y discriminación étnica están más correlacionadas con la función 1, mientras las demás variables están más presentes en la función $2^{17}$. La primera función diferencia al grupo 2 del 1 y el 3 (al ser sus centroides respectivos $0,875,-0,738$ y -10,245), mientras que la segunda función distingue al grupo 1 en relación con los grupos 2 y 3 (siendo sus centroides -2,037, 0,511 y 1,351). La utilidad de las dos funciones discriminantes es después confirmada por la proporción de casos que son correctamente clasificados mediante su aplicación: el 69,7\% de la muestra de análisis y el $71,2 \%$ de la muestra de validación. En la validación cruzada lo fue el 69,7 y el $76,4 \%$, respectivamente. Estos porcentajes superan el que se obtendría por mera casualidad, es decir, sin la ayuda de las funciones discriminantes ${ }^{18}$.

${ }^{16}$ Este índice representa el efecto discriminatorio total de cada variable en el conjunto de las funciones discriminantes significativas. Su valor absoluto carece de significado real, aunque permite conocer la posición relativa de cada variable en cada función.

${ }_{17}$ Los coeficientes estandarizados de las funciones discriminantes canónicas expresan la contribución relativa de la variable en cada función. Pero, al verse afectados por la correlación de la variable con las demás incluidas en la función, se sigue la recomendación de Klecka (1980) y Cea (2002) de interpretar con preferencia los coeficientes de estructura, cuyo valor no está afectado por las interrelaciones entre las variables. Expresa las correlaciones bivariables de las variables predictoras con las funciones discriminantes. Sólo se consideran significativos los coeficientes $\geq 0,30$. Su cuadrado proporciona el porcentaje de varianza que la variable independiente comparte con la función discriminante.

${ }_{18} \mathrm{Al}$ haberse dividido la muestra en dos submuestras, se utiliza como preferente el criterio de casualidad proporcional, que se estima en la muestra de validación: $C_{p r o}=p_{1}^{2}+p_{2}^{2}+p_{3}^{2}=0,549$. Esta proporción es algo más de un $25 \%$ inferior a las obtenidas con el empleo de las funciones discriminantes. Para comprender el proceso analítico seguido, véase Cea D’Ancona (2002). 


\section{TABLA F}

Composición de las funciones discriminantes

\begin{tabular}{|c|c|c|c|c|c|c|c|}
\hline \multirow[b]{2}{*}{ Dimensiones } & \multicolumn{3}{|c|}{ Función discriminante 1} & \multicolumn{3}{|c|}{ Función discriminante 2} & \multirow[b]{2}{*}{$\begin{array}{c}\text { Indice } \\
\text { potenc. } \\
\text { compuesto }\end{array}$} \\
\hline & $\begin{array}{c}\text { Coeficiente } \\
\text { estanda- } \\
\text { rizado }\end{array}$ & $\begin{array}{c}\text { Coeficiente } \\
\text { de } \\
\text { estructura }\end{array}$ & $\begin{array}{l}\text { Indice } \\
\text { potenc. } \\
\text { simple }\end{array}$ & $\begin{array}{c}\text { Coeficiente } \\
\text { estanda- } \\
\text { rizado }\end{array}$ & $\begin{array}{c}\text { Coeficiente } \\
\text { de } \\
\text { estructura }\end{array}$ & $\begin{array}{l}\text { Indice } \\
\text { potenc. } \\
\text { simple }\end{array}$ & \\
\hline \multicolumn{8}{|l|}{ Muestra de análisis } \\
\hline Derechos sociales .................. & 1,207 & $0,688^{*}$ & 0,392 & $-0,189$ & $-0,649$ & 0,072 & 0,464 \\
\hline Derechos de ciudadanía .......... & 0,602 & 0,039 & 0,001 & 0,761 & $0,499^{*}$ & 0,043 & 0,044 \\
\hline 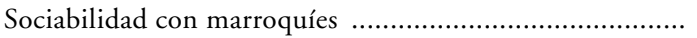 & $-0,516$ & $-0,045$ & 0,002 & $-0,368$ & $-0,297^{*}$ & 0,015 & 0,017 \\
\hline 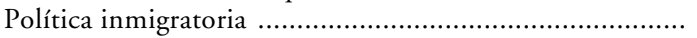 & 0,606 & 0,102 & 0,009 & 0,681 & $0,409^{*}$ & 0,029 & 0,038 \\
\hline Imagen tópica negativa .......................................... & $-0,405$ & $-0,059$ & 0,003 & $-0,462$ & $-0,230^{*}$ & 0,009 & 0,012 \\
\hline 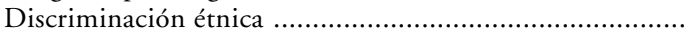 & 0,298 & $0,125^{*}$ & 0,013 & $-0,101$ & $-0,037$ & 0,0002 & 0,013 \\
\hline \multicolumn{8}{|l|}{ Muestra de validación } \\
\hline Derechos sociales ..................... & 1,057 & $0,734^{*}$ & 0,421 & $-0,261$ & $-0,593$ & 0,077 & 0,498 \\
\hline 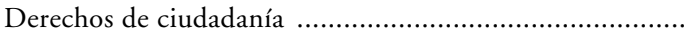 & 0,569 & 0,071 & 0,004 & 0,705 & $0,456^{*}$ & 0,046 & 0,050 \\
\hline Sociabilidad con marroquíes ....................................... & $-0,480$ & $-0,125$ & 0,012 & $-0,515$ & $-0,326^{*}$ & 0,023 & 0,035 \\
\hline 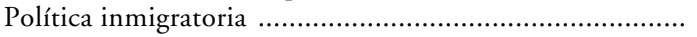 & 0,506 & 0,113 & 0,010 & 0,659 & $0,343^{*}$ & 0,026 & 0,036 \\
\hline Imagen tópica negativa & $-0,304$ & $-0,011$ & 0,0001 & $-0,509$ & $-0,252^{*}$ & 0,014 & 0,014 \\
\hline 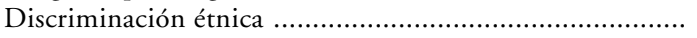 & 0,377 & $0,170^{*}$ & 0,023 & $-0,016$ & $-0,103$ & 0,002 & 0,025 \\
\hline
\end{tabular}

* Mayor correlación absoluta entre cada variable y cualquier función discriminante.

a Valor de potencialidad de la variable $i$ en la función = coeficiente de estructura ${ }^{2} \times$ autovalor relativo de la función discriminante. El autovalor relativo es igual al autovalor de la correspondiente función ( 1 o 2$)$ entre la suma de todos los autovalores de las funciones discriminantes significativas (en la muestra de análisis son, respectivamente, 0,828 y 0,172; en la muestra de validación, 0,781 y 0,219).

b Índice de potencialidad de cada variable en todas las funciones discriminantes. 


\section{CONCLUSIÓN}

De los análisis realizados se extraen dos conclusiones principales. Una atañe a la limitación de las encuestas tradicionales para captar una actitud contraria a la inmigración. En el análisis de conglomerados $k$-medias sólo un $6 \%$ de los encuestados queda clasificado como contrario o reacio a la inmigración (muestra menor simpatía hacia los marroquíes, manifestando una mayor preocupación por la convivencia con ellos; su valoración de la inmigración es negativa, siendo favorable al endurecimiento de la política inmigratoria y a la restricción de los derechos sociales y de ciudadanía de los inmigrantes; está más afectado por una imagen tópica negativa del inmigrante y por el temor a su asentamiento; aprueba la existencia de partidos racistas y no considera que las agresiones contra los inmigrantes sean un problema). Dos, el análisis discriminante confirma, en consonancia con las tesis defendidas por las nuevas formas de racismo, que son los items relativos a derechos sociales y de ciudadanía (en especial los primeros) los de mayor utilidad en la diferenciación de la actitud ante la inmigración (precisamente las dos dimensiones latentes que mayor porcentaje de varianza explicaban en el análisis de componentes principales). Le siguen las preguntas relativas a política inmigratoria, que son, a su vez, las que mayor variabilidad obtienen en las respuestas (véase Valles, Cea e Izquierdo, 1999). En cambio, los items relativos a distancia social, que tradicionalmente están presentes en la generalidad de las encuestas de actitudes y prejuicios étnicoraciales, se sitúan en cuarto lugar en efectividad en la diferenciación de la actitud declarada ante la inmigración. La realización posterior de un análisis discriminante, pero con las 41 variables empíricas, vuelve a incidir en lo mismo. Las 13 variables que muestran poder discriminatorio significativo son, por orden de importancia: vivienda digna, votar municipales, educación pública, número de inmigrantes, traer a su familia, valoración inmigración, casar con marroquí, trabajo en igualdad, leyes inmigración, cobrar paro, votar elecciones generales, supresión fronteras UE y afiliarse a partidos políticos ${ }^{19}$. La efectividad manifiesta de los distintos indicadores de racismo debería considerarse en el diseño de la encuesta, si quiere mejorarse su utilidad en la captación de la actitud «real» ante la inmigración.

19 La proporción de casos que son correctamente clasificados mediante la aplicación de las funciones discriminantes derivadas se eleva ahora hasta el $84,4 \%$ de los casos agrupados originales, y el $82,8 \%$ de los casos agrupados mediante validación cruzada. 


\section{BIBLIOGRAFÍA}

Alvira Martín, F. (1977): «La relación entre actitudes y conducta», Revista Española de la Opinión Pública, 49, 33-52.

ASEP (1998): Actitudes hacia los inmigrantes, Madrid, Ministerio de Trabajo y Asuntos Sociales, Colección Observatorio Permanente de la Inmigración, n. ${ }^{\circ} 2$.

Barbadillo GriñÁN, P. (1997): Extranjería, racismo y xenofobia en la España contemporánea. La evolución de los setenta a los noventa, Madrid, CIS, Colección Monografías, n. ${ }^{\circ} 154$.

BLASCO, M. (1992): «Inmigrantes en España: una historia de desencuentros», Alfoz, 91-92, 60-70.

Calvo Buezas, T. (1990): El racismo que viene. Otros pueblos y culturas vistos por profesores y alumnos, Madrid, Tecnos.

- (2000): Inmigración y racismo. Así sienten los jóvenes del siglo XXI, Madrid, Cauce Editorial.

Cea D'AnCona, M.a A. (1996/2001): Metodología cuantitativa. Estrategias y técnicas de investigación social, Madrid, Síntesis.

- (2002) Análisis multivariable. Teoría y práctica en la investigación social, Madrid, Síntesis.

Colectivo IOÉ (1995): Discurso de los españoles sobre los extranjeros. Paradojas de la alteridad, Madrid, CIS, Colección Opiniones y Actitudes, n. ${ }^{\circ} 8$.

- (2001): Mujer, inmigración y trabajo, Madrid, IMSERSO, Colección Inmigración y Refugio, n. ${ }^{\circ} 2$.

Díez NiCOlÁs, J. (1999): Los españoles y la inmigración, Madrid, IMSERSO, Colección Observatorio Permanente de la Inmigración, n. ${ }^{0} 7$.

Díez Nicolás, J., y Ramírez Lafita, M. J. (2001): La voz de los inmigrantes, Madrid, IMSER$\mathrm{SO}$, Colección Inmigración y Refugio, n. ${ }^{\circ} 4$.

Dovidio, J., y Gaertner, S. (comps.) (1986): Prejudice, discrimination and racism, Nueva York, Academic Press.

GAVIRIA, M. (1992): «La contradicción entre los precarizados y los excluidos españoles y los inmigrantes económicos», Alfoz, 91-92, 134-137.

Gimeno Giménez, L. (2001): Actitudes hacia la inmigración. Relación entre las investigaciones cualitativas y cuantitativas, Madrid, CIS, Colección Opiniones y Actitudes, n. ${ }^{\circ} 34$.

IZQUIERDO, A. (1996): La inmigración inesperada, Madrid, Trotta.

KATZ, D. (1974): «El enfoque funcional en el estudio de las actitudes», en J. R. Torregrosa (comp.), Teoría e investigación en la psicología social actual, Madrid, Instituto de la Opinión Pública, pp. 275-296.

KLECKA, W. R. (1980): Discriminant analysis, Beverly Hills, Sage.

KleinPenning, G., y HAGENDOORN, L. (1993): «Forms of racism and the cumulative dimension of ethnic attitudes», Social Psychology Quartely, 56 (1), 21-36.

Lamberth, J. (1980): Psicología social, Madrid, Ediciones Pirámide, S.A., 3.a ed.

LEAL, J. (1997): "Consideraciones residenciales e integración de los inmigrantes y definición de las políticas de actuación pública», en J. Leal y C. Mayeur (comps.), Vivienda e integración social de los inmigrantes. Seminario europeo, Madrid, Ministerio de Trabajo y Asuntos Sociales, pp. 127-140.

Martínez Veiga, U. (1997): "Alojamiento de los inmigrantes en España», en J. Leal y C. Mayeur (comps.), Vivienda e integración social de los inmigrantes. Seminario europeo, Madrid, Ministerio de Trabajo y Asuntos Sociales, pp. 85-114.

Mateos, A., y Moral, F. (2000): Europeos e inmigrantes. La Unión Europea y la inmigración extranjera, Madrid, CIS, Colección Opiniones y Actitudes, n. ${ }^{\circ} 28$.

McBroom, W. H., y ReEd, F. W. (1992): «Towards a reconceptualization of attitude behavior consistency», Social Psychology Quartely, vol. 55 (2), 205-216.

Meertens, R. W., y Pettigrew, T. F. (1997): «Is subtle prejudice really prejudice?», Public Opinion Quartely, 61, 54-71.

Morales, J. F. (1996): «El prejuicio racial como actitud negativa», en J. F. Morales y S. Yubero (comps.), Del prejuicio al racismo: perspectivas psicosociales, Cuenca, Ediciones de la Universidad de Castilla-La Mancha, pp. 11-22. 
Morales, J. F., y PÁez, D. (1996): «Estereotipos, discriminación y relaciones intergrupos en España y Latinoamérica», en R. V. Bourhis y J. P. Leyens (comps.), Estereotipos, discriminación y relaciones entre grupos, Madrid, McGraw Hill, pp. 1-22.

Navas, M. a S. (1998): "Nuevos instrumentos de medida para el nuevo racismo», Revista de Psicología Social, 13 (2), 233-239.

Newell, R. (1993): "Questionnaires», en N. Gilbert (comp.), Researching social life, Londres, Sage, pp. 94-115.

Oskamp, S. (1991): Attitudes and opinions, Englewood Cliffs, Prentice Hall, 2. ${ }^{\mathrm{a}}$ ed.

PAstor Ramos, G. (1978): Conducta interpersonal. Ensayo de psicología social sistemática, Salamanca, Universidad Pontificia de Salamanca.

PÉrEZ, J. A. (1996): «Nuevas formas de racismo», en J. F. Morales y S. Yubero (comps.), Del prejuicio al racismo: perspectivas psicosociales», Cuenca, Ediciones de la Universidad de Castilla-La Mancha, pp. 79-102.

Pettigrew, T., y Meertens, R. W. (1995): «Subtle and blatant prejudice in Western Europe», European Journal of Social Psychology, 25, 57-75.

RAMírez GoICOECHEA, E. (1996): Inmigrantes en España: vidas y experiencias, Madrid, CIS, Colección Monografías, n. ${ }^{\circ} 147$.

Ros García, M. (1981): «Las escalas de actitudes (1)», en J. F. Morales Domínguez (comp.), Metodología y teoría de la psicología, Madrid, UNED, pp. 215-231.

RUEDA, J. F., y NAVAS, M. (1996): «Hacia una evaluación de las nuevas formas de prejuicio racial: las actitudes sutiles del racismo", Revista de Psicología Social, 11 (2), 131-149.

SCHUMAN, H., y PRESSER, S. (1996): Questions \& answers in attitude surveys: experiments on question form, wording and context, Thousand Oaks, Sage.

SOLÉ, C. (1997): «La inmigración en las ciudades españolas», en J. Leal y C. Mayeur (comps.), Vivienda e integración social de los inmigrantes. Seminario europeo, Madrid, Ministerio de Trabajo y Asuntos Sociales, pp. 45-60.

Solé, C., y Herrera, E. (1991): Trabajadores extranjeros en Cataluña, Madrid, CIS, Colección Monografías, n. ${ }^{\circ} 116$.

VAlles, M. S.; CeA, M. ${ }^{a}$ A., e IZQuierdo, A. (1999): Las encuestas sobre inmigración en España y Europa, Madrid, Ministerio de Trabajo y Asuntos Sociales, Colección Observatorio Permanente de la Inmigración, n. ${ }^{\circ} 3$.

\section{ABSTRACT}

During the last few years there has been an increase in criticisms of the efficiency of conventional surveys in the measurement of «real» attitudes towards immigration. This study evaluates the degree of effectiveness of the indicators traditionally included in such surveys. Analysed here are CIS surveys (studies 2214, 2383 and 2498), which are compared with those carried out by CIRES/ASEP, CEMIRA and Eurobarometers of the European Communities. Through an analysis of principal components of the 41 indicators selected from the first CIS study, 10 dimensions of the concept of racism are obtained. The contribution of each dimension is verified using a discriminatory analysis. In harmony with the new proposals for racism, the items relating to social rights and citizenship are the most useful in measuring attitudes towards immigration, followed by those relating to immigration policy, to the detriment of traditional indicators of racism. Furthermore, the analysis of $K$-means conglomerates confirms the limitation of such surveys for capturing the attitude against immigration (only $6 \%$ of interviewees are classified as being against immigration). The conclusion reached through these analyses is that there is a need to introduce modifications into the measuring instrument so as to improve the harnessing of the «real» attitude towards immigration. 